\title{
EXPLORING INERTIA IN A TYPICAL STATE ORGANISATION
}

\author{
G J LOUW \\ Department of Industrial Psychology, \\ Vista University (Port Elizabeth Campus) \\ N MARTINS \\ Department of Industrial and Organisational Psychology, \\ University of South Africa
}

\begin{abstract}
Those organisations which do not change according to environmental pressures, suffer from organisational inertia. The purpose of this study is to explore the manifestation of organisational inertia in the target organisation. The target population for this study was a group of trainees, representing the geographic and demographic levels of a particular state department. In South Africa, surveys of this nature were only executed in the corporate sector. The results indicate that organisational inertia is a phenomenon that affects both corporate and governmental organisations.
\end{abstract}

\section{OPSOMMING}

Organisasies wat nie ooreenkomstig omgewingsdruk verander nie, ly aan organisasietraagheid. Die doel van die studie is om organisasietraagheid te konseptualiseer en die manifestasie daarvan in die teikenorganisasie te ondersoek. Die teikenpopulasie bestaan uit 'n groep kursusgangers wat die demografiese en geografiese samestelling van ' $\mathrm{n}$ tipiese staatsdepartement verteenwoordig. In Suid -Afrika is navorsing van hierdie aard nog net in die korporatiewe sektor uitgevoer. Die resultate toon aan dat organisasietraagheid ' $\mathrm{n}$ faktor is wat beide die korporatiewe omgewing en staatsorganisasies beïnvloed.

Organisations are under tremendous pressure to adapt to a continuous and increasing number of changes in the environment. In most instances, organisations are aware of these environmental pressures, but do not change accordingly (Hammer, 1997). In many cases, organisational focus is only on external forces instead of both external and internal (Jones, 2000). The question arises which force, external or internal, demands change in organisations. Research (Conner \& Lake, 1998; Fomburn, 1992) revealed that in most instances demands for change within organisations may be initiated either by external or by internal forces. However, Kinnear and Roodt (1998) confirmed that external forces usually trigger change while internal forces tend to prevent change. Thus, the efforts to overcome resistance to change should be focused on the human component of the organisation (Kinnear \& Roodt, 1998).

The above phenomenon is the result of a concept known as "organisational inertia" which refers to forces inside an organisation that cause resistance to change (Jones, 2000). The evolutionary steps the term "organisational inertia" took will not be expounded here, but it will be shown that the term "inertia" in an organisational context has featured in several forms in literature reviews, such as "organisational responsiveness", "organisational learning disabilities", "organisational viscosity", "organisational momentum" and "structural inertia". The difficult terminology attached to this concept is comprehensively summarised in recent research publications (Kinnear \& Roodt, 1998; Roodt, Kinnear, Erwee, Smith, Lynch \& Millett, 2001). In this summarised context, organisational inertia indicated the tendency to remain within the status quo and the resistance to strategic renewal outside the existing frame of strategy (Huff, Huff \& Thomas, 1992).

The inertia phenomenon is hallmarked by its inherent momentum, either retarding change or contributing to the forward movement of organisations (Fomburn, 1992). The momentum relevant to inertia is that it reinforces the status quo. The organisational forces which are supposed to initiate stable structures and processes generate resistance to change, because they protect and maintain the status quo (Kelly \& Amburgey, 1991).

Requests for copies should be addressed to: N Martins, Department of Industrial Psychology, UNISA, PO Box 392, UNISA, 0003
Inertia is a vicious circle in which organisations are trapped. It means that certain forces impede change while others gather momentum for the continuation of the status quo. As a result of this, change-facilitating forces have limited impact on organisational management practices and the phenomenon becomes a growing and integral part of the system (Connor \& Lake, 1988). Kinnear and Roodt (1998) found that various synonyms or antonyms often overlap with the existing theory or merely adding a different dimension to theories on inertia.

French and Bell (1999) draw a distinction between the different types of change that can take place in an organisation. Day-today- adaptation- to-change demands can be referred to as incremental or evolutionary changes. On the other hand, organisational transformation or second order change, which can be defined in terms of comprehensive, drastic and radical alterations imposed on organisations as a whole, take place after an organisation maintained the status quo for too long. Therefore, drastic change become a means for survival or to create a state of equilibrium.

The change efforts referred to in this article apply to any type of change that is initiated and ranging from either incremental, evolutionary adaptation efforts, or radical second-order changes.

Louw (1995) confirms that the phenomenon of organisational inertia stems from individual resistance to change, which can be traced back to the psycho-analytic theory. This theory postulates that resistance to change is an individual response to uncertainty or fear of unexpected events, or when the outcome of change demands cannot be predicted. Such sluggishness may be manifested in group as well in organisational activities. Kreitner and Kinicki (1998) describe the phenomenon in terms of a vertical continuum which may vary from individual acceptance to active resistance. Those who do not directly resist, but who may experience uncertainty, are unproductive. The situation converts into individual pathology which can result in an "individual crisis".

Senge (1994) argues that organisations which do not change may face immediate death, because it is a matter of survival of the fittest. According to Senge (1994), the largest industrial enterprises have an average lifetime of forty years. The corrective actions that may be needed to get the organisation out of the turmoil, namely organisational transformation, may be 
dangerous if not correctly managed. Maurer (1996) estimates a success rate not more than nine percent for organisations who opt for transformation. Stewart (1999) is more lenient and estimates it on fifty percent. The main reason for failure is that organisations forget that the human side must also be managed into transition. Governmental organisations can survive for a longer period in comparison with corporate organisations, due to the "sponsorship" of the taxpayer's money.

To deal with difficulties in the change process itself, Lewin (1951) suggests change in organisations as a three-stage process. The first is to unfreeze the organisation's behaviour from the status quo. Then movement takes place into new behaviour. The last stage is to refreeze behaviour at a new level. A very strong characteristic of this change process is the movement from one equilibrium stage to another. It creates the perception that movement from the one stage should not take place unless it occurs from a position of equilibrium. However, it seems that the change process can keep on swinging from one vicious circle to another. The reasons for this can be linked to the impatience of management with employees' uncertainties, a lack of systems thinking in terms of business/human resource management and the fact that change is not monitored as a multi-systems flow process. The most important factor here may be the consolidated human behaviour into the future state.

An example of a multiple systems flow is depicted in figure 1 as postulated by the Burke and Litwin (1992) model of Organisational Performance and Change. Concerning the business processes, the figure is self-explanatory. The model explains the causality in the organisation and the feedback loops between the different systems. It consists the following dimensions:

i) The transformational variables (depicted in the upper part of figure 1) which represents the external environment, mission, leadership and organisational culture. These variables refer to areas which are suppose to be sensitive to alteration needs caused by internal or external environmental focus and which require new sets of behaviour. ii) Transactional variables (depicted in the lower part of figure 1) which consist of structure, management practices, systems, work unit climate, task requirements, motivation, and individual needs and values. These variables are affected by short term interaction between individuals and groups.

According to Burke (1992) diagnostics should be focused on these systems to establish the organisation's readiness to change. However, it seems that the unfreezing stage as postulated by Lewin (1951), may be the most problematic due to the cyclical nature of the change process. As mentioned earlier, movement from one stage to another should occur between stages of equilibrium. Maurer (1996) warns that the movement can slide into diseliquibrium.

To drive the change process successfully, Maurer (1996, pp. 2932) explains the change process in terms of the "cycle of change". It postulates the monitor of the change process in terms of the "big picture" or "gestalt". This change process is shown in figure 2 .

The cycle can be explained as follows:

Random incidents (one o'clock on the cycle). Only senior management may be aware of problems that may require change. Most staff are unaware of any problems.

Recognition (three o' clock). Recognition is the most crucial stage of the cycle. Senior management committed to be open and talk about the problems. Once everyone sees the same picture, it becomes possible to get all the role players aligned to move around the cycle together. During this stage, it is important that everyone recognizes the situation and realizes the need for a shift. When this shift occur, people's views are transformed.

Initial actions (five o'clock). Once the issue is recognized, energy starts to build. Everyone wants to do something. Here conversations emerge out of the situation in an effort to address the problem. Such conversations can only take place after everyone had recognized the seriousness of the status quo.

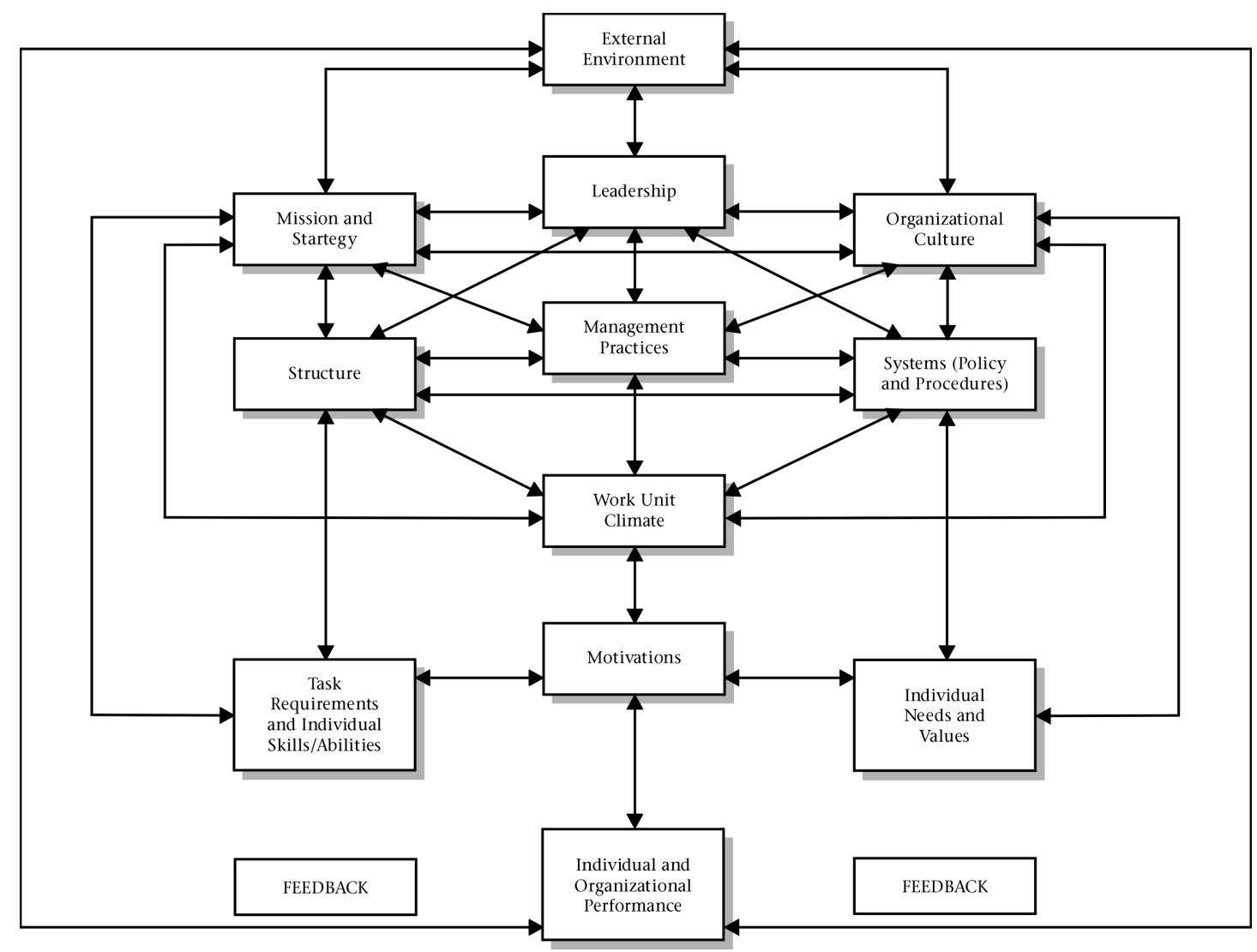

Figure 1: Burke and Litwin (1992) model for organizational performance and change 


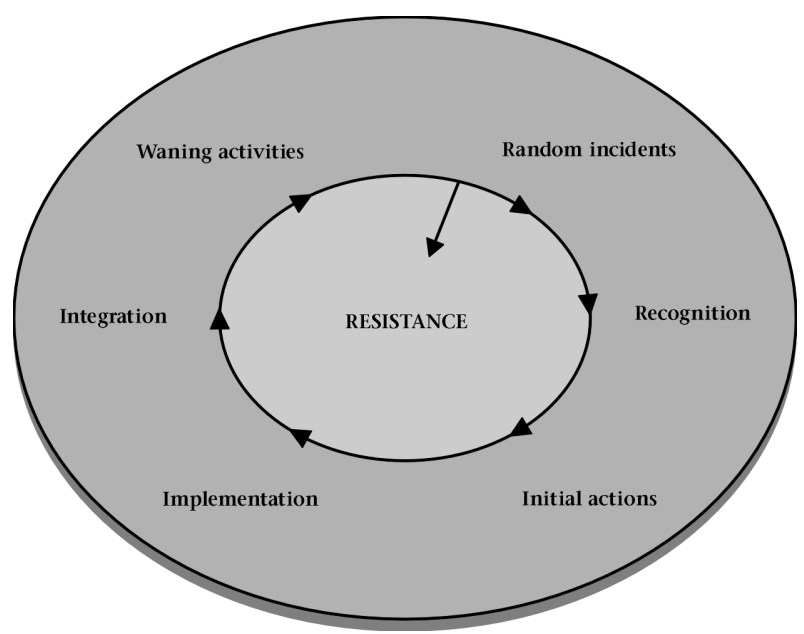

Figure 2: Cycle of change (Maurer, 1996, p. 30)

Implementation (seven o'clock). During this stage the idea to address the situation is rolled out. The plan how to tackle the problem will be announced and implemented immediately. The implementation of any change initiative will fail at this stage if any individual employee does not understand and support the initiative. Even unions, who agreed up to now, can derail the process. The phase seems to correspond with Lewin's (1951) stage of unfreezing. Thus, during this stage, the organisation must be in total readiness to enhance the new vision.

Integration (nine o'clock). During this stage, the new initiative forms part of the business cycle. If the organisation experiences full integration, almost no resistance may exist. If any uncertainty or resistance is detected, the initiative may be hampered.

Waning activities (eleven o'clock). The transition stage between integration and the waning activities take place at this stage. This is also an important part of the process. If resistance of any nature is not identified and addressed properly, the whole process moves back to the stage of "random incidents". The implication thereof is that the new vision or change initiative is back to the original stage without any progress. This is the stage where the status quo is still in existence.

In this regard, Scott and Jaffe (1991, pp. 51-52) distinguish between individual as well as group manifestations of organisational inertia. These manifestations are displayed in table 1.

The cycle of change supports the theory of inertia which further implies that the dynamics of change can hamper change processes itself. For example, committed employees who can propel any change initiative successfully, may become involved in the political dynamics within an organisation. Political activities can obstruct change initiatives. One obvious reason for obstructing the change process, is uncertainty (Maurer 1996).

Although organisational transformation is a process that usually follows as an initiative to drive the organisation out of the vicious cycle of inertia, the individual or (organisational) inertia can emerge if the human component is not managed properly (French \& Bell, 1999). To overcome this problem, accurate diagnostic information is needed to drive the change and development process. Kinnear and Roodt (1998, pp. 44-54) developed an instrument to measure the existence of inertia within the target organisation. This instrument is known as the "Organisational Inertia Scale" which is based on the key systems within an organisation as depicted in figure 1.
TABLE 1

INDIVIDUAL AND GROUP MANIFESTATIONS

\begin{tabular}{ll}
\hline Individual Manifestations & Group manifestations \\
\hline Complaints & Accidents \\
Errors & Increased absenteeism \\
Anger & Sabotage \\
Stubbornness & Increase in union activity \\
Apathy & Lower productivity \\
Absence due to illness & \\
Withdrawal & \\
\hline
\end{tabular}

(Adapted from Scott \& Jaffe, 1991, pp. 51-52)

The results of the "Organisational Inertia Scale -OIS" provide diagnostic information regarding the target organisation. From the results a facilitator can see whether an organisation is ready to change (Kinnear \& Roodt, 1998). Organisational systems that reflect negative results can be isolated. Multiple organisational interventions can be targeted to move the organisation out of diseliquibrium.

As a result of the new National Constitution (Act 108 of 1996) which was promulgated in South Africa, it is assumed that most corporate and public sector organisations should change in response to this "environmental obligation" which is contained in the act.

The main objective of this study was to target a typical public sector organisation in obtaining a sample respondents that represents this particular sector, as well post levels between the lowest and junior management. For this study, the focus was specifically to determine whether the same systemic variables, that are identified by Kinnear and Roodt, (1998) in the corporate sector as causal factors of organisational inertia, are also manifested in a sample obtained in a public sector organisation.

The aim of this study is thus to explore the manifestation of organisational inertia in the target organisation, because the latter represents a government organisation, and similar studies have not been conducted in such work environments as yet.

\section{METHOD}

\section{Sample}

The subjects for the study were 347 employees in a typical state department who represent the demographic composition of the organisation. This particular sample was obtained at an inservice training institution. Table 2 reflects the various biographical categories of each group. The age category of 25 to 34 years is the largest while the category 18 to 24 years representing the smallest. Male respondents dominate the sample with $88,8 \%$

Although the sample is covering all language groups in South Africa, Afrikaans comprises the largest proportion with Tshivenda as the minority. The tenure category, representing the proportion between 6 to 10 years, is in the majority. Despite a missing value of 1,4 percent, a proportion of 88,8 percent of the respondents have a qualification of matric or higher. To explore the leadership/management training levels, a proportion of 67,6 percent indicated that they haven't attended either of the courses while 20,3 percent indicated that they attended at least an internal management training course. 
TABLE 2

BIOGRAPHICAL DATA

\begin{tabular}{lrr}
\hline & \multicolumn{2}{c}{ AGE } \\
\hline & N & $\%$ \\
$18-24$ Years & 9,0 & 2,6 \\
$25-34$ Years & 162,0 & 46,7 \\
$35-44$ Years & 135,0 & 38,9 \\
$45-54$ Years & 18,0 & 5,2 \\
$55+$ & 0,0 & 0,0 \\
Missing & 23,0 & 6,6 \\
Total & 347,0 & 100,0 \\
\hline & & GENDER \\
\hline & N & $\%$ \\
Male & 308,0 & 88,8 \\
Female & 38,0 & 11,0 \\
Missing & 1,0 & 0,2 \\
Total & 47,0 & 100,0 \\
\hline
\end{tabular}

\section{LANGUAGE}

\begin{tabular}{lrr}
\hline & $\mathrm{N}$ & $\%$ \\
Afrikaans & 85,0 & 24,5 \\
Sepedi & 25,0 & 7,0 \\
Setswana & 56,0 & 16,1 \\
Xitsonga & 7,0 & 2,0 \\
siXhosa & 61,0 & 17,6 \\
SiSwazi & 8,0 & 2,3 \\
English & 24,0 & 7,0 \\
Sesotho & 26,0 & 7,5 \\
Tsivenda & 3,0 & 0,9 \\
IsiNdebele & 4,0 & 1,2 \\
IsiZulu & 43,0 & 12,4 \\
Other & 3,0 & 0,9 \\
Missing & 2,0 & 0,6 \\
Total & 347,0 & 100,0 \\
\hline & & TENURE \\
\hline & N & $\%$ \\
Less than 3 years & 7,0 & 2,0 \\
3 - 5 years & 36,0 & 10,4 \\
6 - 10 years & 122,0 & 35,2 \\
11 - 15 years & 102,0 & 29,4 \\
16 - 20 years & 65,0 & 18,7 \\
More that 20 years & 14,0 & 4,0 \\
Missing & 1,0 & 0,3 \\
Total & & 100,0 \\
\hline & & \\
& &
\end{tabular}

\section{QUALIFICATIONS}

\begin{tabular}{lrr}
\hline & N & \% \\
Lower than matric & 36,0 & 9,8 \\
Matric & 193,0 & 55,6 \\
Matric with diploma & 88,0 & 25,4 \\
B-degree & 17,0 & 4,9 \\
Post graduate & 10,0 & 2,9 \\
Missing & 5,0 & 1,4 \\
Total & 347,0 & 100,0
\end{tabular}

\begin{tabular}{lcccr}
\hline \multicolumn{5}{c}{ COURSES ATTENDED } \\
\hline Rank & Management & Leadership & No Course & Total \\
\hline & N & N & N & N \\
\hline Entry level & 3,0 & 1,0 & 11,0 & 15,0 \\
Second level & 26,0 & 10,0 & 119,0 & 155,0 \\
Third level & 21,0 & 15,0 & 55,0 & 91,0 \\
Junior Management & 17,0 & 3,0 & 34,0 & 64,0 \\
Civil/Professional & 0,0 & 0,0 & 0,0 & 0,0 \\
Other & 1,0 & 1,0 & 5,0 & 7,0 \\
Missing & 0,0 & 0,0 & 2,0 & 2,0 \\
Total & 68,0 & 40,0 & 226,0 & 334,0 \\
Percentage & 20,3 & 11,9 & 67,6 & 100,0 \\
\hline
\end{tabular}

\section{Measuring instrument}

To identify the constructs applicable to organisational inertia, the "Organisational Inertia Scale" (OIS), developed by Kinnear and Roodt (1998), was used with the permission of the developers. The questionnaire consists of 109 items, representing the synergised and overlapping dimensions, adapted by Kinnear and Roodt (1998) on the Burke-Litwin (1992) model of organisational change and development. This model is depicted in terms of its systems flow in Figure 2. In the South African context, the OIS was standardised on samples representing the corporate sector and respondents from post levels between junior-or middle management (Kinnear \& Roodt, 1998). The dimensions measured by the OIS are as follows:

- External environment. Any outside condition or situation that influences the performance of the organisation.

- The business and change strategy (mission and strategy). The necessity of a change strategy in terms of the external and internal demands for change.

- Change leadership. Executive behaviour that provides direction and encourages others to take needed action. Data gathering focuses on perceptions of executive practices and values.

- Supportiveness of organisational culture. The overt and covert rules, values and principles that guide organisational behaviour.

- Business composition. The structure and arrangement of functions and people into specific areas and levels of responsibility, decision-making, authority and relationships.

- Change management practices. What managers do in the normal course of events to use the human and material resources at their disposal to carry out the organisation's strategy.

- Change related systems. Policies, mechanisms, compensation, financial resources and any other reward systems that are conducive to change efforts.

- Work unit orientation. A supportive climate, availability of resources, level of expertise of change agents and the work unit's acceptance of change initiatives.

- Job/task requirements and individual skills/abilities. This dimension concerns what is often referred to as job-person match.

- Motivation. Aroused behavioural tendencies to move toward goals, take needed action and persist until satisfaction is attained.

- Personal impact of the change initiative. Aspects that may have an impact on individual and organisational performance. For example, people's existing status, earnings job security and power networks.

- Individual needs and values. The ability to cope and the impact of psychological factors (emotional impact) that provide desire and worth for individual/personal actions or thoughts.

The instrument gives a summary of the individual respondent's perception and experience of the change process. The 
questionnaire is a Likert seven-point intensity response scale, anchored at either side in terms of Schepers's (1992) requirements for measuring instruments. The items are formulated in question format. To overcome the error of item prejudice, the scale is numbered in a reversed order (from left to right with decreased intensity). High scores on the scale indicate an individual's satisfaction with the questions set, and vice versa. The instrument proved to be reliable with an internal consistency of 0,981 (Cronbach Alpha) (Kinnear \& Roodt, 1998, p. 50).

\section{Procedure}

Respondents were gathered in a lecture room. The nature and purpose of the research were explained to them. Full instructions on how to complete the questionnaire were given verbally. Respondents were given the opportunity to take part in the research project voluntarily. Confidentiality and anonymity were assured by requesting respondents not to write their names on the questionnaire. No time limitation was set to complete the questionnaire. The questionnaires were distributed in the lecture room and collected after it was completed.

\section{Statistical analysis}

The measuring instrument generated an enormous amount of data. Therefore, the publication of all of them is beyond the scope of this article. However, it is available for inspection if necessary.

In order to confirm the reliability of the instrument for the purpose of this study, a principal factor analysis with a Varimax rotation was conducted. The analysis was subjected to Kaiser's normalization. A three level rotation was done to determine the measurement consistency of the instrument as such, as well as for the sub-scales and individual items respectively.

TABLE 3

\section{FACTOR MATRIX}

\begin{tabular}{lcc}
\hline & FACTOR I & FACTOR II \\
\hline Factor I & 0,773 & 0,634 \\
Factor II & $-0,634$ & 0,773 \\
\hline
\end{tabular}

Hair, Anderson, Tatham and Black (1995, p. 374) have requirements for assumptions relevant to reliability indexes for analysis. For example, an index of 0,90 or above is "marvelous," 0,80 or above is "meritorious", 0,70 or above is "middling," 0,60 or above is "mediocre," and 0,50 or above is "miserable." Those lower than 0,50 is unacceptable.

The nature of the OIS Likert-scale makes it difficult to obtain results that meet the requirements of normality. In this case, it was decided to conduct significance tests by means of Pearson's Chi-square $\left(X^{2}\right)$ on those items that reflects seriousness in terms of inertia's existence.

The "Statistica (1995)" software was used to conduct the analysis.

\section{RESULTS}

Tables 3, 4 and 5 show the reliability indexes of the OIS as it was rotated on the three levels respectively.

The matrix in table 3 confirms an inter-correlation of 0,773 (Alpha) for the instrument as a whole. It means that the results are referring to only one common factor, namely the phenomenon of organisational inertia. Table 4 depicts the reliability indexes of the underlying dimensions of inertia as reflected in the 12 sub-scales of the instrument. Indexes in this table varies between 0,677 for factor $G$, which is the lowest, to 0,896 for factor $F$ representing the highest index for all sub-scales.
TABLE 4

ReLIABILITY INDEX OF SUB-SCALES

\begin{tabular}{ll}
\hline Factor & Alpha \\
\hline A & 0,845 \\
B & 0,820 \\
C & 0,870 \\
D & 0,846 \\
E & 0,837 \\
F & 0,896 \\
G & 0,677 \\
H & 0,730 \\
I & 0,851 \\
J & 0,870 \\
K & 0,828 \\
L & 0,871 \\
\hline
\end{tabular}

Although table 5 is reflecting the reliability indexes of the individual items on the OIS, it also displays all other descriptive statistics for further discussions in the article.

TABLE 5

Descriptive Statistics

\begin{tabular}{lcccccc}
\hline ITEM & N & X & SD & Alpha & Skewness & Kurtosis \\
\hline \multicolumn{7}{c}{ A. Inertia factors in change strategy } \\
\hline A1 & 339 & 5,56 & 1,19 & 0,834 & $-1,13$ & 0,09 \\
A2 & 345 & 5,17 & 2,00 & 0,848 & $-0,82$ & $-0,53$ \\
A3 & 342 & 4,48 & 2,05 & 0,831 & $-0,35$ & $-1,07$ \\
A4 & 341 & 3,68 & 1,97 & 0,831 & 0,19 & $-1,08$ \\
A5 & 343 & 3,90 & 1,96 & 0,833 & 0,02 & $-1,07$ \\
A6 & 345 & 3,71 & 1,94 & 0,830 & 0,23 & $-1,02$ \\
A7 & 343 & 4,22 & 2,06 & 0,830 & $-0,13$ & $-1,20$ \\
A8 & 346 & 3,60 & 1,98 & 0,831 & 0,26 & $-1,06$ \\
A9 & 343 & 3,88 & 2,01 & 0,832 & 0,12 & $-1,16$ \\
A10 & 342 & 3,60 & 2,00 & 0,838 & 0,32 & $-1,09$ \\
A11 & 344 & 4,46 & 1,90 & 0,837 & $-0,24$ & $-1,00$ \\
A12 & 345 & 4,63 & 2,03 & 0,830 & $-0,39$ & $-1,09$ \\
A13 & 344 & 4,54 & 1,92 & 0,838 & $-0,32$ & $-0,99$ \\
\hline
\end{tabular}

B. Environmental influences as inertia factor

\begin{tabular}{lllllll}
\hline B1 & 343 & 3,88 & 1,93 & 0,808 & 0,04 & $-1,06$ \\
B2 & 346 & 4,45 & 2,06 & 0,789 & $-0,34$ & $-1,08$ \\
B3 & 345 & 4,29 & 1,88 & 0,791 & $-0,18$ & $-1,02$ \\
B4 & 342 & 4,34 & 1,78 & 0,799 & $-0,18$ & $-0,83$ \\
B5 & 346 & 4,38 & 1,86 & 0,794 & $-0,22$ & $-1,02$ \\
B6 & 344 & 4,11 & 1,95 & 0,794 & $-0,10$ & $-1,10$ \\
B7 & 342 & 3,58 & 1,91 & 0,797 & 0,20 & $-1,00$ \\
\hline
\end{tabular}

C. Inertia factors surrounding change leadership

\begin{tabular}{lllllll}
\hline C1 & 341 & 3,62 & 2,17 & 0,855 & 0,27 & $-1,33$ \\
C2 & 338 & 3,20 & 2,04 & 0,856 & 0,56 & $-0,95$ \\
C3 & 337 & 3,59 & 1,93 & 0,861 & 0,36 & $-0,98$ \\
C4 & 338 & 3,19 & 1,90 & 0,864 & 0,53 & $-0,85$ \\
C5 & 338 & 2,95 & 1,95 & 0,865 & $0,69 *$ & $-0,71$ \\
C6 & 339 & 3,17 & 1,84 & 0,864 & 0,55 & $-0,67$ \\
C7 & 340 & 3,46 & 1,96 & 0,870 & 0,31 & $-1,06$ \\
C8 & 337 & 3,01 & 1,95 & 0,852 & $0,69 *$ & $-0,71$ \\
C9 & 337 & 3,12 & 1,89 & 0,855 & 0,60 & $-0,66$ \\
C10 & 337 & 3,33 & 1,90 & 0,857 & 0,40 & $-0,89$ \\
C11 & 339 & 3,19 & 1,83 & 0,858 & 0,48 & $-0,75$ \\
C12 & 345 & 3,39 & 1,91 & 0,865 & 0,42 & $-0,84$
\end{tabular}


D. Inertia factors in organisational culture

\begin{tabular}{lllllll}
\hline D1 & 345 & 3,22 & 1,80 & 0,828 & 0,55 & $-0,67$ \\
D2 & 347 & 3,18 & 1,97 & 0,819 & 0,50 & $-0,96$ \\
D3 & 345 & 3,13 & 1,89 & 0,814 & 0,55 & $-0,83$ \\
D4 & 344 & 3,09 & 1,85 & 0,827 & 0,58 & $-0,71$ \\
D5 & 345 & 2,99 & 1,75 & 0,833 & $0,54 *$ & $-0,69$ \\
D6 & 344 & 3,32 & 1,83 & 0,822 & 0,42 &,- 084 \\
D7 & 345 & 3,37 & 1,85 & 0,849 & 0,41 & $-0,81$ \\
D8 & 345 & 3,57 & 1,99 & 0,826 & 0,21 & $-1,16$
\end{tabular}

E. Inertia factors in business composition

\begin{tabular}{lllllll}
\hline E1 & 342 & 3,72 & 1,96 & 0,839 & 0,13 & $-1,13$ \\
E2 & 342 & 3,35 & 1,93 & 0,811 & 0,43 & $-0,97$ \\
E3 & 343 & 3,38 & 1,92 & 0,807 & 0,38 & $-0,98$ \\
E4 & 343 & 3,28 & 1,90 & 0,814 & 0,48 & $-0,88$ \\
E5 & 344 & 3,28 & 1,93 & 0,805 & 0,48 & $-0,89$ \\
E6 & 343 & 3,37 & 1,87 & 0,819 & 0,31 & $-0,98$ \\
E7 & 342 & 3,39 & 1,92 & 0,819 & 0,42 & $-0,90$ \\
E8 & 343 & 3,31 & 1,93 & 0,829 & 0,48 & $-0,90$
\end{tabular}

F. Inertia factors in change management practices

\begin{tabular}{lrrrrrr}
\hline F1 & 343 & 3,43 & 1,93 & 0,890 & 0,42 & $-0,89$ \\
F2 & 3,23 & 1,87 &, 653 & 0,48 & $-0,81$ & \\
F3 & 346 & 3,07 & 1,92 & 0,626 & $0,63 *$ & $-0,72$ \\
F4 & 343 & 3,13 & 1,90 & 0,888 & 0,58 & $-0,71$ \\
F5 & 344 & 3,20 & 2,00 & 0,538 & 0,53 & $-0,91$ \\
F6 & 343 & 3,25 & 2,05 & 0,544 & 0,55 & $-0,96$ \\
F7 & 346 & 3,77 & 2,09 & 0,381 & 0,13 & $-1,26$ \\
F8 & 345 & 3,21 & 2,01 & 0,491 & 0,57 & $-0,92$ \\
F9 & 344 & 3,62 & 2,08 & 0,475 & 0,27 & $-1,20$ \\
F10 & 344 & 3,10 & 1,82 & 0,552 & 0,62 & $-0,56$ \\
F11 & 341 & 3,26 & 1,87 & 0,599 & 0,46 & $-0,86$ \\
F12 & 344 & 3,20 & 1,79 & 0,686 & 0,50 & $-0,64$ \\
F13 & 343 & 3,34 & 1,82 & 0,670 & 0,44 & $-0,77$ \\
F14 & 341 & 3,47 & 1,75 & 0,629 & 0,33 & $-0,72$ \\
F15 & 340 & 3,36 & 1,83 & 0,618 & 0,44 & $-0,74$ \\
\hline
\end{tabular}

G. Inertia factors in change related systems

\begin{tabular}{lllllll}
\hline G1 & 339 & 2,99 & 1,77 & 0,634 & $0,68 *$ & $-0,44$ \\
G2 & 340 & 2,79 & 1,77 & 0,597 & $0,76^{*}$ & $-0,48$ \\
G3 & 341 & 2,91 & 1,88 & 0,560 & $0,76 *$ & $-0,53$ \\
G4 & 343 & 3,10 & 1,99 & 0,637 & 0,60 & $-0,88$ \\
G5 & 344 & 3,23 & 1,98 & 0,693 & 0,55 & $-0,87$ \\
\hline
\end{tabular}

H. Inertia factors in work unit change organisation

\begin{tabular}{lllllll}
\hline H1 & 345 & 3,88 & 2,12 & 0,730 & 0,12 & $-1,34$ \\
H2 & 343 & 3,66 & 2,06 & 0,698 & 0,20 & $-1,22$ \\
H3 & 343 & 3,43 & 2,10 & 0,725 & 0,37 & $-1,16$ \\
H4 & 343 & 3,34 & 2,09 & 0,705 & 0,44 & $-1,10$ \\
H5 & 343 & 2,98 & 1,93 & 0,667 & $0,63 *$ & $-0,80$ \\
H6 & 339 & 2,96 & 1,99 & 0,683 & $0,68 *$ & $-0,78$ \\
H7 & 342 & 3,20 & 1,98 & 0,693 & 0,57 & $-0,81$ \\
H8 & 342 & 3,42 & 2,05 & 0,698 & 0,37 & $-1,12$ \\
\hline
\end{tabular}

I. Inertia factors in job requirements

\begin{tabular}{lllllll}
\hline I1 & 343 & 3,66 & 2,04 & 0,848 & 0,28 & $-1,13$ \\
I2 & 343 & 3,79 & 2,08 & 0,845 & 0,18 & $-1,23$ \\
I3 & 342 & 3,83 & 2,02 & 0,840 & 0,11 & $-1,21$ \\
I4 & 343 & 4,45 & 2,03 & 0,839 & $-0,26$ & $-1,19$ \\
I5 & 342 & 4,48 & 1,96 & 0,837 & $-0,27$ & $-1,03$ \\
I6 & 342 & 4,78 & 1,93 & 0,830 & $-0,51$ & $-0,83$ \\
I7 & 340 & 4,61 & 1,96 & 0,826 & $-0,34$ & $-1,10$ \\
I8 & 343 & 4,52 & 1,99 & 0,831 & $-0,28$ & $-1,12$ \\
I9 & 340 & 4,48 & 2,00 & 0,832 & $-0,30$ & $-1,08$ \\
I10 & 344 & 4,24 & 2,11 & 0,832 & $-0,15$ & $-1,31$ \\
I11 & 341 & 4,08 & 2,03 & 0,846 & $-0,11$ & $-1,16$
\end{tabular}

J. Motivation for change as inertia factor

\begin{tabular}{lllllll}
\hline J1 & 341 & 4,39 & 2,05 & 0,854 & $-0,19$ & $-1,22$ \\
J2 & 338 & 4,46 & 2,02 & 0,833 & $-0,25$ & $-1,17$ \\
J3 & 340 & 4,51 & 2,04 & 0,846 & $-0,31$ & $-1,14$ \\
J4 & 341 & 4,35 & 2,09 & 0,849 & $-0,21$ & $-1,24$ \\
J5 & 342 & 4,28 & 2,10 & 0,847 & $-0,18$ & $-1,29$ \\
J6 & 342 & 4,09 & 2,07 & 0,859 & $-0,04$ & $-1,24$ \\
\hline
\end{tabular}

K. Personal experience of change as inertia factor

\begin{tabular}{lllllll}
\hline K1 & 343 & 3,83 & 2,14 & 0,801 & 0,12 & $-1,29$ \\
K2 & 340 & 3,95 & 2,16 & 0,794 & 0,08 & $-1,36$ \\
K3 & 339 & 4,02 & 2,09 & 0,811 & 0,03 & $-1,28$ \\
K4 & 340 & 4,24 & 2,01 & 0,803 & $-0,06$ & $-1,19$ \\
K5 & 338 & 3,86 & 2,04 & 0,821 & 0,09 & $-1,23$ \\
K6 & 332 & 3,88 & 1,99 & 0,803 & 0,14 & $-1,12$ \\
K7 & 335 & 3,78 & 2,02 & 0,802 & 0,17 & $-1,13$ \\
\hline
\end{tabular}

L. Emotional experience of change as inertia factor

\begin{tabular}{lllllll}
\hline L1 & 327 & 3,61 & 2,10 & 0,855 & 0,28 & $-1,22$ \\
L2 & 323 & 3,53 & 1,97 & 0,867 & 0,29 & $-1,03$ \\
L3 & 326 & 3,23 & 2,01 & 0,859 & 0,47 & $-1,07$ \\
L4 & 324 & 3,68 & 2,04 & 0,860 & 0,18 & $-1,18$ \\
L5 & 326 & 3,29 & 1,99 & 0,861 & 0,42 & $-0,98$ \\
L6 & 325 & 3,52 & 2,11 & 0,846 & 0,30 & $-1,17$ \\
L7 & 325 & 3,85 & 2,01 & 0,859 & 0,04 & $-1,16$ \\
L8 & 325 & 3,73 & 2,04 & 0,849 & 0,15 & $-1,20$ \\
L9 & 325 & 3,71 & 2,11 & 0,855 & 0,11 & $-1,25$ \\
\hline
\end{tabular}

The "Statistica (1995)" software programme was used to conduct the analysis.

The reliability indexes among the 109 items, as reflected in table 5 varies between 0,870 and 0,381. Bartholomew, Henderson and Marcia (2000, p. 298) argue that reliabilities between 0,80 and 0,60 are acceptable. Those lower than 0,60 are also acceptable as long as the testing of a hypotheses is not involved. Thus, during this research it was decided that the relevant items were highly reliable during the development of the questionnaire and that the low indexes in this study should not be omitted. Due to the nature of the questionnaire that was characterized by a reversed intensity, the researchers were interested in items with a positive skewness index from 0,5 and higher. Such indexes demonstrated a majority of responses closer to option one (1) on the seven-point Likert-scale. To determine a cut-off for the mean, the authors were guided by previous research. In similar studies (Burke, Coruzzi \& Church, 1996; Church, Margiloff \& Coruzzi, 1995) item means lower than 3,06 were considered as items that reflect concern for the purpose of organisational development interventions. To be conservative, a mean of 3,08 and lower was set for this research. Kurtosis indicates a measure of the peakedness of a distribution. In this study the distributions vary between 0,09 (the most leptokurtic) and -1,36 (the most platykurtic). Due to the nature of the measuring instrument that usually generates data which tend to group or cluster at either extreme end of the scale, none of the items reflected a normal distribution (mesokurtic distribution).

An inspection of results in table 5 reveals that some items create data with concern in terms of the change process as a whole. Table 6 is a summary of items below the 3,08 cut-off. It can also be relayed to the particular dimension the OIS measures as well as the specific sub-system as explained in this article in terms of the Burke-Litwin (1992) model of Organisational Change and Development. 
TABLE 6

ITEMS BELOW CUT-OFF MEAN

\begin{tabular}{lll}
\hline Items & Dimensions & Variable \\
\hline C5,C8 & Leadership & Transformational \\
D5 & Organisation culture & Transformational \\
F3 & Management practices & Transactional \\
G1,G2,G3 & Organisational systems & Transactional \\
H5,H6 & Work unit climate & Transactional \\
\hline
\end{tabular}

A further interpretation attached to this data is that development interventions would usually be focussed in these areas within the target organisation, due to the fact that low means is a signal of sluggishness of organisational systems relevant to the change process (Burke et al., 1996). All items listed in table 6 have means below the 3,08 cut-off set for research purposes.

The questions in the OIS referring to the items depicted in table 6 , are displayed in table 7 to give direct support for any conclusions in this article.

\section{TABLE 7}

QUESTIONS RELEVANT TO ITEMS THAT CAUSE CONCERN

\begin{tabular}{l} 
ITEM QUESTION \\
\hline C5 Do employees have confidence in top management's ability to manage \\
changes? \\
C8 Do top management show commitment to the change initiative, by \\
practising what they preach? \\
D5 Are creative contributions to business improvement rewarded? \\
F3 Was the change initiative planned well? \\
G1 Does the company's compensation system support the change \\
initiative? \\
G2 Are employees who implement the changes rewarded for it? \\
G3 Have sufficient human resources been allocated to manage the change \\
initiative? \\
H5 Are some people of your team selected as change agents (individuals \\
who will drive the change initiative within your team? \\
H6 Are those selected fully trained to act as trained agents?
\end{tabular}

TABLE 8

Cross tabulations

\begin{tabular}{lllll}
\hline $\begin{array}{l}\text { Biographic } \\
\text { Dimension }\end{array}$ & $\begin{array}{l}\text { Dimension on } \\
\text { "Organisational } \\
\text { Inertia Scale" }\end{array}$ & $\begin{array}{l}\text { Confidence } \\
\text { level }\end{array}$ & P-Value & $\begin{array}{l}\text { Significant/ } \\
\text { No significance }\end{array}$ \\
\hline $\begin{array}{l}\text { Courses } \\
\text { attended }\end{array}$ & Leadership (C5) & 5 & 0,906022 & no \\
$\begin{array}{l}\text { Educational } \\
\text { level }\end{array}$ & $\begin{array}{l}\text { Organisational } \\
\text { culture (D5) }\end{array}$ & 5 & 0,874334 & no \\
Tenure & $\begin{array}{l}\text { Management } \\
\text { practices (F3) }\end{array}$ & 5 & 0,215841 & no \\
Educational & $\begin{array}{l}\text { Organisational } \\
\text { systems }\end{array}$ & 5 & 0,170926 & no \\
(G2) & & & \\
\hline
\end{tabular}

To rule out the possibility of chance, data listed in table 6 was subject to Pearson's chi square $\left(X^{2}\right)$ cross-tabulations with biographic dimensions in table 2 . All these item means were below the cut-off mean of 3,08 . The results of the cross-tabulations are shown in table 8 . The confidence level of 0,05 in this exercise confirms that the results obtained are not due to chance.

\section{DISCUSSION}

The results in table 5 confirm that the respondents do support the changes initiated by the organisation (see items A1 and A2) but also prove that there are some reasons for concern with the process drive itself.

The data summarised in tables 6 and 8 confirm that the respondents were not satisfied with dimensions like leadership and organisational culture which represent the transformational variables as conceptualised by Burke and Litwin (1992). A similar argument can be raised in terms of management practices, organisational systems and work unit climate which represent the transactional variables conceptualised by the same authors. The impact there-of is that the target organisation is not ready for change and that the the "unfreezing" stage of change will be problematic. In fact, the organisation will maintain the status quo unless target interventions could be implemented to drive the change process.

As from an interpretation of the responses generated by means of the OIS, it can be assumed that respondents are uncertain about the leadership vision for the change process. It also reflects the perception that previous change initiatives were unsuccessful and that top management do not posses the ability to manage the change initiatives properly. The fact that respondents feel that management is not honest enough with the change objectives implemented, can also be interpreted as a matter of insufficient communication between management and ground level employees.

The scores relevant to the dimension "organisational culture" (D5) give the impression that employees are not given an opportunity to do experiments in the work context to find solutions for the daily problems experienced. The findings relevant to "organisational culture" supports a possible leadership crisis is experiencing. The data generated by the questionnaire reflects an assumption that a learning culture is still not being introduced and that creativity is not rewarded within the organisational context. The classification of leadership and organisational culture as transformational variables reveals that the target organisation does not possess the ability to respond to environmental pressures.

Management practices can be seen as the tools to deal proactively and reactively with the pressures from inside and outside the organisation. However, the sample in this study shows a lack of participative management practices. Further more, role models are not clearly identified to promote interaction and drive during the change process. A lack of management skills are manifested. This leads to a lack of guidance to subordinates which is crucial during the change process.

The respondents revealed the insufficient allocation of financial resources to reward extraordinary change successes initiated by employees. The non-existence of supporting change systems, as indicated by respondents, may result in stagnated organisational systems.

The presence of a negative organisational climate is a causal effect of weak leadership and a lack of interaction between management and subordinates. The weakening climate is suppressing inter-employee relationships as well as the trust relationships between supervisors and subordinates.

Although item means on and below 3,08 were selected for research purpose in this article, items with means up to 3,5 (out of the Likert scale of seven) could also been isolated for intervention purposes, because item means up to 3,5 are still not convincing that all are well with the change process in the target organisation. If this was the case the following items would have been selected for intervention purposes: 
- Items $\mathrm{C} 2, \mathrm{C} 3, \mathrm{C} 4, \mathrm{C} 5, \mathrm{C} 6, \mathrm{C} 7, \mathrm{C} 8, \mathrm{C} 9, \mathrm{C} 10, \mathrm{C} 11, \mathrm{C} 12$ (Leadership)

- Items D1,D2,D3,D4,D5,D6,D7D,D8 (Organisation culture)

- Items $\mathrm{E} 2, \mathrm{E} 3, \mathrm{E} 4, \mathrm{E} 5, \mathrm{E} 6, \mathrm{E} 7, \mathrm{E} 8$ (Business composition)

- Items $\mathrm{F} 1, \mathrm{~F} 2, \mathrm{~F} 3, \mathrm{~F} 4, \mathrm{~F} 5, \mathrm{~F} 6, \mathrm{~F} 7, \mathrm{~F} 8, \mathrm{~F} 9, \mathrm{~F} 10, \mathrm{~F} 11, \mathrm{~F} 12, \mathrm{~F} 13, \mathrm{~F} 14, \mathrm{~F} 15$ (Change management practices)

- Items G1,G2,G3,G4,G5 (Organisational systems)

- Items $\mathrm{H} 4, \mathrm{H} 5, \mathrm{H} 6, \mathrm{H} 7, \mathrm{H} 8$, (Work unit climate)

With the mentioned negative aspects in mind, it will not be unjustified to argue that the target organisation is heading for a state of organisation pathology. Organisation dysfunctions like these have serious threats to employee physiological and mental wellbeing (Herman, 1963; Kets de Vries \& Miller, 1984; Krantz, 1985).

The outcome of the empirical study supports the theory regarding the dynamics within the organisational change process. It also underlines the psycho-socio dynamics of change. Ignorance of these components will inevitably result in the failure of change and transformation interventions (Burke, 1992).

According to the findings of this study, it can be concluded that organisational inertia is a phenomenon that affects both corporate and public sector organisations. However, the results of this study and those of Kinnear and Roodt (1998) differ partly in terms of organisational inertia's manifestation in organisational systems. Whereas Kinnear and Roodt (1998) pointed out that the variables named management practices, change-related systems, work-unit climate, task requirements and individual experience of change (variables labelled "transactional variables" by Burke and Litwin) is mostly causal to inertia, this study reveals similarity with regard to management practices, change related systems and work unit climate. Besides these similarities, variables like individual skills/abilities as well as individual and organisational performance can be added to transactional variables that are causal to inertia.

What appears to be different from Kinnear and Roodt's (1998) findings, is that leadership and organisational culture (labelled as "transformational variables" by Burke and Litwin, 1992), are more prominent in this study. The latter's prominence supports Maurer's (1996) argument explaining that change in organisations should be initiated by management/leadership as the driving force. Further, change should be facilitated through socialisation processes in order to create a new corporate culture that may reduce or eliminate restraining forces during the cyclical phase of the change process.

This research has succeeded in providing a holistic view of organisational inertia as a logical factor manifested in different organisational environments. It added value to the accuracy of the OIS as an instrument that was only representing particular samples before this study was conducted.

It can be expected that the improperly management of change in organisations can cause psychological dysfunction, it is suggested that pathology as a phenomenon also be investigated in organisations that undergo major change processes.

Although it can be concluded that the research objectives reached its goals, the study may be hampered by the 9,8 percent respondents who have qualifications lower than matric (grade 12). This level of literacy may exert a negative influence on the interpretation of the research items.

\section{REFERENCES}

Bartholomew, K., Antonia, J.Z. \& Marcia, J.E. (2000). Coded semi-structured interviews in social psychological research. In H.T. Reis \& C.M. Judd (Eds.), Handbook of research methods in social and personality psychology (pp. 286-312). Cambridge: Cambridge University Press.
Burke, W.W. (1992). Organization development. Reading, MA: Addison-Wesley.

Burke, W.W., Coruzzi, C.A. \& Church, A.H. (1996). The organizational survey as an intervention for change. In A.I. Kraut (ed.), Organizational surveys: Tools for assessment and change (pp. 41-66). Jossey-Bass: San Francisco.

Burke, W.W. \& Litwin, G.H. (1992). A causal model of organizational performance and change. Journal of Management, 18 (3), 500-523.

Church, A.H., Margiloff, A. \& Coruzzi, C.A. (1995). Using surveys for change: An applied example in a pharmaceuticals organization. Leadership and Organization Development Journal, 16 (4), 3-11.

Conner, P.E. \& Lake, L.K. (1998). Managing organization change. New York: Praeger.

French, W.L. \& Bell. C.H. (1999). Organization development: Behavioral science interventions for organization improvement (6 ${ }^{\text {th }}$ Edition). Upper Saddle River, NJ: PrenticeHall.

Fomburn, C.J. (1992). Leading corporate change. New York McGraw-Hill

Hair, J.F., Anderson, R.E., Tatham, R.L. \& Black, W.C. (1995). Multivariate data analysis with readings (4th Edition). Englewood Cliffs, NJ: Prentice Hall.

Hammer, M. (1997). Beyond reengineering: How the processcentered organization is changing our work and our lives. New York: Harper-Collins.

Herman, C.F. (1963). Some consequences of crisis which limit the viability of organisations. Administration Science Quarterly, 8 (2), 61-82.

Huysamen, G. K. (1991). Beskrywende statistiek vir die sosiale wetenskappe ( 2 de hersiene uitgawe). Pretoria: Academica.

Huff, J.O., Huff, A.S. \& Thomas, H. (1992). Strategic renewal and the interaction of cumulative stress and inertia. Strategic Management Journal, 13 (4), 55-75.

Jones, G.R. (2000). Organizational theory: Text and cases (3rd ed.). Upper Saddle River, N J: Prentice-Hall.

Kelly, D. \& Amburgery, T.H. (1991). Organizational inertia and momentum: A dynamic model of strategic change. Academy of Management Journal, 34 (2), 591-612.

Kets de Vries, M.F.R. \& Miller, D. (1984). Neurotic style and organizational pathology. Strategic management journal, 5 (35), 35-55

Kinnear, C. \& Roodt, G. (1998). The development of an instrument for measuring organisational inertia. Journal of Industrial Psychology, 24 (2), 44-54.

Krantz, J. (1985). Group process under conditions of organizational decline. The Journal of Applied Behavioural Science, 21 (1), 1-7.

Kreitner, R. \& Kinicki, A. (1998). Organizational behavior (4th Edition). New York: McGraw-Hill.

Lewin, K. (1951). Field Theory in Social Science. New York: Harper.

Louw, D. A. (1995). Suid-Afrikaanse handboek vir abnormale gedrag. Halfweghuis: Southern.

Maurer, R. (1996). Beyond the wall of resistance. Austin, TX: Bard Books.

Roodt, G., Kinnear, C., Erwee, D., Smith, B., Lynch, B. \& Millet, B. (2001). Measurement of organisational inertia: Portability of a South African scale in an Australian context. Journal of Industrial Psychology, 27 (2), 57-61.

Scott, C.D. \& Jaffe, D.T. (1991). Managing Organizational Change. CA: Kogan Page.

Schepers, J.M. (1992). Toetskonstruksie: Teorie en praktyk. Johannesburg: R.A.U. Drukpers.

Senge, P.M. (1994). The fifth discipline: The art and practice of the learning organization. New York: Currency.

Statistica. (1995). Statistical software for Windows. Release 5.5. Tulsa, OK: Statsoft Inc.

Stewart, T.A. (1999). Rate your readiness to change. Fortune, 129 (3), 106-109. 